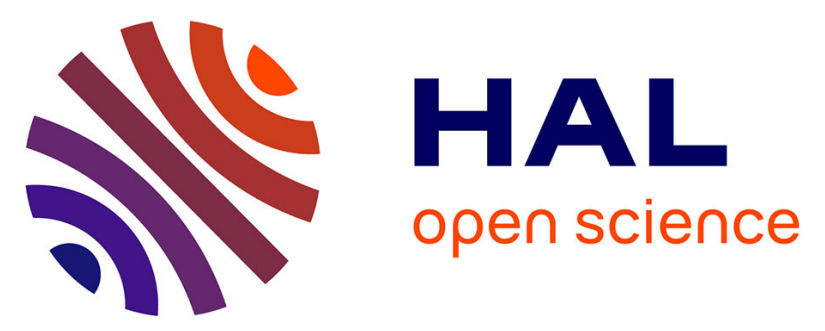

\title{
Highly sensitive detection of NO2 gas using BGaN/GaN superlattice-based double Schottky junction sensors
}

Chris Bishop, Jean-Paul Salvestrini, Yacine Halfaya, Sundaram Suresh, Youssef El Gmili, Laetitia Pradere, Jean Yves Marteau, Badreddine Assouar, Paul L Voss, Abdallah Ougazzaden

\section{To cite this version:}

Chris Bishop, Jean-Paul Salvestrini, Yacine Halfaya, Sundaram Suresh, Youssef El Gmili, et al.. Highly sensitive detection of NO2 gas using BGaN/GaN superlattice-based double Schottky junction sensors. Applied Physics Letters, 2015, 106 (24), pp.243504. 10.1063/1.4922803 . hal-01170536

\section{HAL Id: hal-01170536 https://hal.science/hal-01170536}

Submitted on 12 Jan 2022

HAL is a multi-disciplinary open access archive for the deposit and dissemination of scientific research documents, whether they are published or not. The documents may come from teaching and research institutions in France or abroad, or from public or private research centers.
L'archive ouverte pluridisciplinaire HAL, est destinée au dépôt et à la diffusion de documents scientifiques de niveau recherche, publiés ou non, émanant des établissements d'enseignement et de recherche français ou étrangers, des laboratoires publics ou privés. 


\title{
Highly sensitive detection of $\mathrm{NO}_{2}$ gas using $\mathrm{BGaN} / \mathrm{GaN}$ superlattice-based double Schottky junction sensors
}

\author{
C. Bishop, ${ }^{1,2}$ J. P. Salvestrini, ${ }^{2,3}$ Y. Halfaya,${ }^{2,4}$ S. Sundaram, ${ }^{2}$ Y. El Gmilii, ${ }^{2}$ L. Pradere,${ }^{4}$ \\ J. Y. Marteau, ${ }^{4}$ M. B. Assouar, ${ }^{5}$ P. L. Voss, ${ }^{1,2}$ and A. Ougazzaden ${ }^{1,2}$ \\ ${ }^{1}$ School of Electrical and Computer Engineering, Georgia Institute of Technology, Atlanta, Georgia 30332, \\ USA \\ ${ }^{2}$ Georgia Tech-CNRS, UMI 2958, 57070 Metz, France \\ ${ }^{3}$ Université de Lorraine, CentraleSupelec, LMOPS, EA4423, 57070 Metz, France \\ ${ }^{4}$ PSA Peugeot Citroën, 75, Avenue de la Grande Armée, Paris 75116, France \\ ${ }^{5}$ CNRS, Inst Jean Lamour, F-54506 Vandoeuvre Les Nancy, France
}

(Received 9 February 2015; accepted 9 June 2015; published online 17 June 2015)

\begin{abstract}
We report a double Schottky junction gas sensor based on a $\mathrm{BGaN} / \mathrm{GaN}$ superlattice and $\mathrm{Pt}$ contacts. $\mathrm{NO}_{2}$ is detected at concentrations from 4.5 to $450 \mathrm{ppm}$ with current responsivity of $6.7 \mathrm{~mA} /\left(\mathrm{cm}^{2} \times \mathrm{ppm}\right)$ at $250{ }^{\circ} \mathrm{C}$ with a response time of $5 \mathrm{~s}$. The sensor is also selective against $\mathrm{NH}_{3}$ at least for concentrations less than $15 \mathrm{ppm}$. The $\mathrm{BGaN}$ layer at the surface increases surface trap density and trap depth, which improves responsivity and high temperature stability while the GaN layer improves the magnitude of the diode current. The BGaN layer's columnar growth structure also causes a Pt morphology that improves $\mathrm{O}^{2-}$ diffusion. (C) 2015 AIP Publishing LLC.

[http://dx.doi.org/10.1063/1.4922803]
\end{abstract}

Nitride-based semiconductors are attractive materials for gas sensing applications due to their wide bandgap properties. Specifically, the high breakdown voltages and thermal stability of these materials make them suitable for high temperature applications in harsh environments (e.g., automotive exhaust systems or engines). Schottky diodes and metal-oxide-semiconductor field-effect transistor (MOSFET) devices using a variety of semiconductor materials have previously been demonstrated for detection of hydrogen and other gases, ${ }^{1-4}$ but their use for $\mathrm{NO}_{2}$ sensing has not been widely explored. One potential application for $\mathrm{NO}_{2}$ sensing is in the selective catalytic reduction of $\mathrm{NO}_{x}$ by injection of $\mathrm{NH}_{3}$ in an automotive exhaust. Requirements for this application are high sensitivity and responsivity to the target gas, high thermal stability, and complete selectivity between $\mathrm{NO}_{x}$ and $\mathrm{NH}_{3}$. The general mechanism of gas detection by Schottky diode sensors is attributed to the dissociation of gas molecules after physisorption on the catalytic Pt surface. ${ }^{5}$ The charged gas ions (negative oxygen ions in the case of $\mathrm{NO}_{2}$ ) then diffuse through available grain boundaries or pores in the $\mathrm{Pt}$ contact and are chemisorbed at available interface traps on the semiconductor surface. The additional negative charge at the interface must be compensated by a more positive depletion region and an increase in the Schottky barrier height (SBH) $\Delta \phi_{B}=\frac{N_{i} \rho \theta}{\epsilon \epsilon_{0}}$, where $N_{i}$ is the interface trap concentration, $\rho$ is the dipole moment between the gas and the traps, and $\theta$ is the fraction of interface traps occupied by gas ions. ${ }^{6}$ The increase of the SBH corresponds to a lowering of the device current. A second mechanism may also occur where the molecule or reaction intermediates interact either capacitively or directly with the interface traps via pores in the metal contact. ${ }^{8}$ Furthermore, the thickness and morphology of the contacts have been shown to affect gas sensitivity ${ }^{9}$ and are a possible strategy for selective detection of different species of gas. To analyze sensor performance, one can measure the absolute current change, $\Delta I=\left|I_{\text {gas }}-I_{0}\right|$, or the relative sensitivity, $\mathrm{S}=\frac{\Delta I}{I_{0}}$, where $I_{0}$ is the initial current when no gas is applied. In order to compare sensors that have different initial current values or measure different concentration ranges, we also can use the sensor responsivity $R=\frac{\Delta I}{\operatorname{area} \times \Delta C}$, where $\Delta \mathrm{C}$ is the change in concentration of gas. Schottky diode sensors based on $4 \mathrm{H}-$ and $6 \mathrm{H}-\mathrm{SiC}$ with a thin $\mathrm{Pt}$ contact were shown to have a rather large value of $\mathrm{S}=19.35 \%$ to $200 \mathrm{ppm} \mathrm{NO}_{2}$ at $300{ }^{\circ} \mathrm{C}^{7}$ but with a very low value of $\mathrm{R}=0.002 \mathrm{~mA}$ $\mathrm{cm}^{-2} \mathrm{ppm}^{-1}$ and slow response time, of the order of several minutes (see Table I). A separate study ${ }^{3}$ using n-type GaN Schottky diode sensors with a $75 \mathrm{~nm}$-thick $\mathrm{Pt}$ contact showed an improved response to $\mathrm{NO}_{2}$ at $300{ }^{\circ} \mathrm{C}$ compared to $\mathrm{SiC}$-based sensors, but a quantitative comparison of the responsivity and/or sensitivity was not possible using the reported metrics. A Pt/AlGaN/GaN high electron mobility transistor (HEMT) structure was shown to exhibit a decreased $\mathrm{S}=10 \%$ due to a higher initial current, but a significantly higher $\mathrm{R}=1.14 \mathrm{~mA} \mathrm{~cm}^{-2} \mathrm{ppm}^{-1}$ at $400{ }^{\circ} \mathrm{C}^{8}$ This tradeoff between the $\Delta \mathrm{I}$ (and thus the responsivity) and sensitivity is explained by the fact that the $\Delta \mathrm{I}$ for Schottky diodes is given by the expression $\Delta \mathrm{I}=\mathrm{I}_{0}\left(\mathrm{e}^{\frac{\Delta \phi_{B}}{k T}}-1\right)$, which is derived from the thermionic emission transport model. Therefore, a high initial current results in high responsivity whereas the sensitivity is increased with a large increase in $\Delta \phi_{B}$ caused by a high concentration of interface traps, which results in a lowering of the initial current. Finding a balance between $\Delta \mathrm{I}$ and $\mathrm{I}_{0}$ is exemplified by the work of Quang et al. ${ }^{10}$ who reached large $\Delta \mathrm{I}$ while maintaining relatively large $\mathrm{I}_{0}$ in $\mathrm{SNO}_{2}$ nanowires-based Schottky junction (SJ) gas sensor, and thus resulting in outstanding values of both sensitivity and responsivity (see Table I). Furthermore, even if limited to very low gas concentration (tens of ppb) and rather low operating temperature $\left(150^{\circ} \mathrm{C}\right)$, the response time $\left(\tau_{r}\right)$ of the device was shown to be relatively fast at 
TABLE I. Comparison of $\mathrm{NO}_{2}$ sensor performances, including sensitivity (S), responsivity $(\mathrm{R})$, response time $\left(\tau_{r}\right)$, and recovery time $\left(\tau_{R}\right)$.

\begin{tabular}{|c|c|c|c|c|c|c|c|c|}
\hline Device & Catalyzer & $I_{0}(\mathrm{~mA})$ & $\Delta I(\mu \mathrm{A})$ & $\mathrm{S}(\%)$ & $\mathrm{R}\left(\frac{\mathrm{mA}}{\left(\mathrm{cm}^{2} \times \mathrm{ppm}\right.}\right)$ & $\mathrm{T}\left({ }^{\circ} \mathrm{C}\right)$ & $\tau_{r} / \tau_{R}(\mathrm{~s})$ & Reference \\
\hline SiC Schottky diode & $\mathrm{Pt}$ & 0.002 & 0.38 & 19.35 & 0.002 & 300 & $90 / 120$ & 7 \\
\hline $\mathrm{SNO}_{2}$ Schottky diode & $\ldots$ & 0.42 & 243 & 58.3 & $\leq 648$ & 150 & $43 / 37$ & 10 \\
\hline AlGaN/GaN HEMT & $\mathrm{Pt}$ & 5 & 500 & 10 & 1.43 & 400 & $\mathrm{n} / \mathrm{a}$ & 8 \\
\hline GaN Schottky diode & $20 \mathrm{~nm} \mathrm{Pt}$ & 11.5 & 370 & 3.2 & 1.14 & 200 & $300 / 300$ & This work \\
\hline \multirow[t]{2}{*}{ BGaN/GaN SL MSM } & $100 \mathrm{~nm} \mathrm{Pt}$ & 7.07 & 2140 & 30 & 6.7 & 250 & $5 / 80$ & This work \\
\hline & & \pm 0.3 & \pm 105 & \pm 1.5 & $\pm \mathbf{0 . 3}$ & & & \\
\hline
\end{tabular}

$43 \mathrm{~s}$ with a recovery time $\left(\tau_{R}\right)$ of $37 \mathrm{~s}$. Finally, Schottky sensors for $\mathrm{NH}_{3}$ detection have also been reported, ${ }^{11}$ but complete selectivity between $\mathrm{NO}_{x}$ and $\mathrm{NH}_{3}$ has not yet been demonstrated with these types of devices.

In this work, we report double $\mathrm{SJ} \mathrm{NO}_{2}$ sensors based on $\mathrm{GaN}$ materials that exhibit large sensitivity and responsivity with tunable electrical conductivity (to adjust $\mathrm{I}_{0}$ ) and carrier trapping efficiency (to adjust $\Delta \phi_{B}$ and thus $\Delta \mathrm{I}$ ). To achieve this, quasi-alloys of $\mathrm{BGaN} / \mathrm{GaN}$ superlattices (SLs) were used as active layers. Indeed, we have shown previously that the electrical conductivity of the BGaN alloy can be tuned over more than seven orders of magnitude using low boron incorporation concentration (less than $2 \%$ ). ${ }^{12}$ Furthermore, we have also shown ${ }^{13,14}$ an enhancement of the $\Delta \phi_{B}$ originating from an increase of the trapping efficiency due to boron incorporation in the BGaN quasi-alloy. BGaN/GaN SL structures allow more flexibility in the tuning of the boron incorporation in thick layers compared to $\mathrm{BGaN}$ monolayers. ${ }^{15}$ We also choose to use a double SJ metal-semiconductor-metal (MSM) design that is more simple to fabricate compared to Schottky diode or HEMT structure. The performance of this device for $\mathrm{NO}_{2}$ detection is compared to double $\mathrm{SJ} \mathrm{Pt} / \mathrm{GaN}$ reference devices that we have fabricated and other reported Schottky and HEMT devices for $\mathrm{NO}_{2}$ detection.

The reference device used in this work is a commercially available $400 \mathrm{~nm}$ thick n-type $\mathrm{GaN}$ (Si-doped). The $\mathrm{BGaN} / \mathrm{GaN}$ SL structure was grown using 10 periods of $20 \mathrm{~nm}$ thick undoped $\mathrm{GaN}$ and $20 \mathrm{~nm}$ thick $\mathrm{BGaN}$ with an average boron concentration of the quasi-alloy of $3.6 \%$. The structure was grown and processed according to the procedure given by Srour et al. ${ }^{13}$ Another device was processed with $20 \mathrm{~nm}$ Pt using the same conditions on the n-type GaN sample. The circular diodes have a $300 \mu \mathrm{m}$ diameter with a $200 \mu \mathrm{m}$ spacing between the two Pt contacts (see Fig. 1(a)).

For experimental testing, the devices were connected with probes in a gas chamber and connected to a Keithley 236 IV measurement system. Gas sources of pure $\mathrm{N}_{2}$ and $450 \mathrm{ppm}$ $\mathrm{NO}_{2}$ with pressure regulators were connected to the testing chamber via a gas blender so that the pressure, concentration, and flow rate were all controlled during the measurements. A flow rate of $100 \mathrm{sccm}$ was used for all measurements.

The $\Delta \mathrm{I}$ and $\mathrm{S}$ of the GaN and $\mathrm{BGaN} / \mathrm{GaN}$ SL devices upon exposure to $450 \mathrm{ppm} \mathrm{NO}_{2}$ gas are shown as a function of temperature in Fig. 1(b).

For the BGaN/GaN SL device with $100 \mathrm{~nm}$ thick $\mathrm{Pt}$ layer, a $\Delta \mathrm{I}$ of $215 \mu \mathrm{A}$ and $\mathrm{S}$ of $12 \%$ were obtained at $25^{\circ} \mathrm{C}$, compared to $14 \mu \mathrm{A}$ and $0.1 \%$, respectively, for the GaN device with a $20 \mathrm{~nm}$ thick Pt layer. It is important to note that the GaN device with a Pt thickness of $100 \mathrm{~nm}$ showed no sensitivity or current change with gas exposure, likely due to a continuous Pt layer with no grain boundaries for oxygen diffusion as shown by scanning electron microscopy (SEM) images of the device surfaces (not shown).

For both samples, the $\Delta \mathrm{I}$ and $\mathrm{S}$ are shown to increase with temperature. In the case of the $\mathrm{BGaN} / \mathrm{GaN}$ SL device, the measured values of $\Delta \mathrm{I}$ fluctuate slightly, which is probably due to motion of the contact point of the electrical probe tips, observed with increasing the temperature. This did not occur with GaN devices which were wire-bonded to the contact pad. Nevertheless, according to these results, the $\Delta \mathrm{I}$ and $\mathrm{S}$ of the $\mathrm{BGaN} / \mathrm{GaN}$ SL device are significantly higher than both the GaN reference device and the devices reported in literature (see Table I), reaching values of $2140 \mu \mathrm{A}$ and $30 \%$, respectively, at $250^{\circ} \mathrm{C}$. This means that the $\mathrm{BGaN}$ superlattice structure offers a good balance for high $\mathrm{S}$ and $\Delta \mathrm{I}$, whereas other devices show a significant tradeoff between the two metrics. The improved sensitivity of the BGaN/GaN SL sensor can be explained by a combination of two mechanisms.
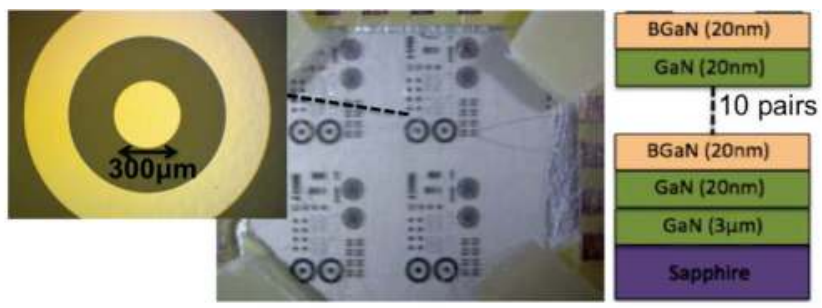

(a)

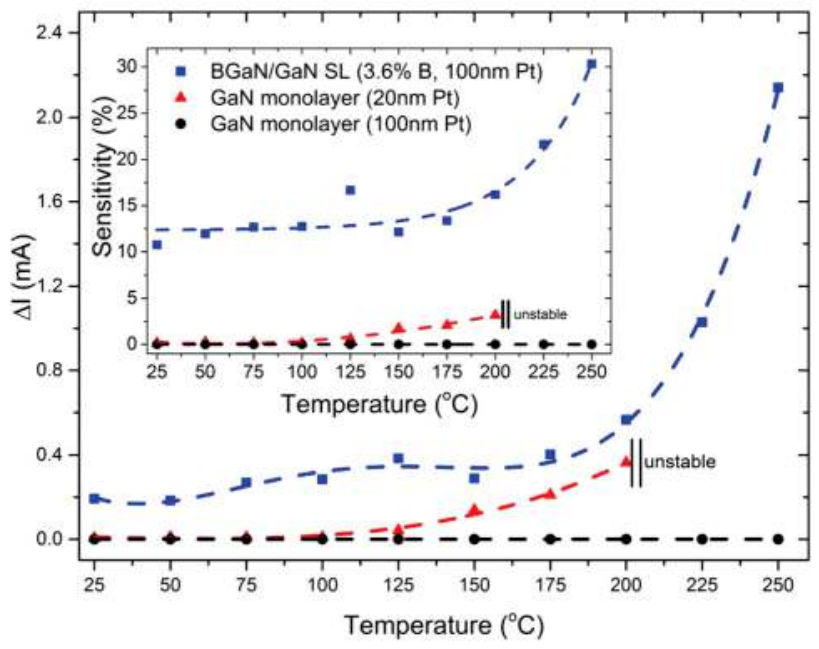

(b)

FIG. 1. (a) Sensor device and (b) comparison of the temperature dependence of $\Delta \mathrm{I}$ and $\mathrm{S}$ (inset) of $\mathrm{BGaN} / \mathrm{GaN} \mathrm{SL}$ and $\mathrm{GaN}$ sensors to $450 \mathrm{ppm} \mathrm{NO} \mathrm{NO}_{2}$ at $5 \mathrm{~V}$ bias. 
The first is that $\mathrm{BGaN}$ material has more interface traps than $\mathrm{GaN}$ and thus more adsorption sites for the oxygen ions. This results in more gas coverage at the interface and a larger SBH change. The secondary advantage of the BGaN layer is that it exhibits columnar growth, decreasing the volume-to-area ratio at the interface. This means that it is possible to have more interface traps within a given area. Additionally, the columnar surface of BGaN causes the Pt layer to have more grain boundaries, increasing the diffusion of the oxygen ions through the Pt contact to the interface traps. Furthermore, $\Delta \mathrm{I}$ is not sacrificed due to the higher-conductivity GaN interlayers in the superlattice structure, which serve to increase the $\mathrm{I}_{0}$. This leads to both high responsivity and sensitivity to $\mathrm{NO}_{2}$ for the $\mathrm{BGaN} / \mathrm{GaN}$ SL sensor, with a responsivity of $6.7 \pm 0.3 \mathrm{~mA}$ $\mathrm{cm}^{-2} \mathrm{ppm}^{-1}$ at $250^{\circ} \mathrm{C}$, as shown in Table I. This is significantly higher than the responsivity for other reported devices except the $\mathrm{SNO}_{2}$ nanowires-based $\mathrm{SJ}$ gas sensor.

For all samples tested, we found that there was a memory effect after gas exposure and that it was necessary to reset the sensor by increasing the temperature and purging the test chamber between each measurement. Temperatures of $100^{\circ} \mathrm{C}$ and $300^{\circ} \mathrm{C}$ were required to reset the $\mathrm{GaN}$ and $\mathrm{BGaN} / \mathrm{GaN}$ SL samples, respectively. This result is consistent with chemisorption at the interface as the mechanism responsible for the SBH change. Chemisorption requires the additional energy present at higher temperatures in order for desorption to break the bonds of absorption. Deep-level transient spectroscopy (DLTS) measurements, not shown here, indicate that electron traps in $\mathrm{BGaN}$ material become deeper with boron incorporation, which can explain the higher reset temperature required for the $\mathrm{BGaN} / \mathrm{GaN} \mathrm{SL}$ sensor. It is to be noticed that the GaN sensor becomes unstable above $200{ }^{\circ} \mathrm{C}$ (see Fig. 1(b)) due to a drift in baseline current, making it impossible to take a reliable measurement at these temperatures. The cause of this drift is currently being explored, but may be due to the thin Pt layer used. After returning to temperatures below $200^{\circ} \mathrm{C}$, the baseline remains stable.

To further analyze the thermal stability of the devices, measurements were taken as a function of applied bias at $150^{\circ} \mathrm{C}$. In SJ device gas sensor, in opposite to $\mathrm{S}$ which is only a function of the change in SBH and is expected to remain constant after a steady state value is obtained, $\Delta \mathrm{I}$ and $\mathrm{R}$ are proportional to $\mathrm{I}_{0}$ and thus their values should increase with increasing bias voltage. The dependence of $\Delta \mathrm{I}$ and $\mathrm{S}$ on applied bias is shown for the $\mathrm{BGaN} / \mathrm{GaN} \mathrm{SL}$ and $\mathrm{GaN}$ sensors at $150^{\circ} \mathrm{C}$ (Fig. 2). As expected, $\Delta \mathrm{I}$ increases with increasing bias voltage up to $5 \mathrm{~V}$ for both devices (see inset), but $\mathrm{S}$ reaches a constant value only for the BGaN/GaN SL device and bias larger than $2 \mathrm{~V}$. On the contrary, the GaN sensor exhibits a maximum $\mathrm{S}$ followed by a decrease at higher voltages. This decrease could be attributed to a temperaturedependent avalanche effect that is proportional to the initial current. ${ }^{16}$ Under high electric fields, there is an increase in tunneling through the barrier and a reduction of the effective barrier height. This additional tunneling current diminishes the effect of the increase in barrier height due to the gas, thereby reducing the sensitivity. At $150^{\circ} \mathrm{C}, \mathrm{BGaN}$ does not exhibit the same avalanche effect due to a lower initial current and therefore does not exhibit the loss in sensitivity at increased voltages as does $\mathrm{GaN}$ at the same temperature. This

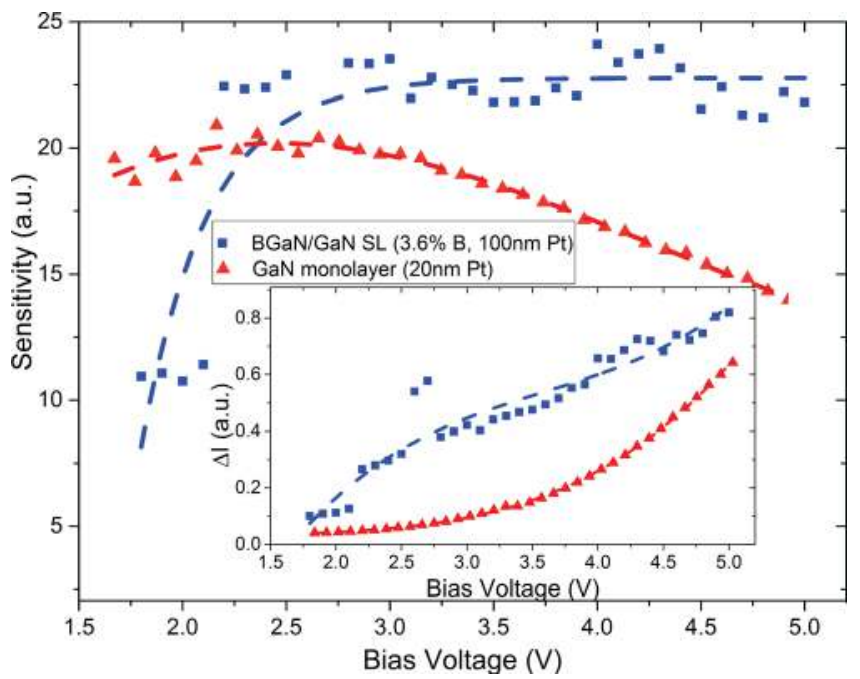

FIG. 2. $\Delta \mathrm{I}$ and $\mathrm{S}$ of the $\mathrm{BGaN} / \mathrm{GaN} \mathrm{SL}$ and $\mathrm{GaN}$ sensors in $450 \mathrm{ppm} \mathrm{NO}_{2}$ as a function of applied bias at $150^{\circ} \mathrm{C}$. Values are given in arbitrary units so that the trends can be placed on the same scale.

result further demonstrates the improved thermal stability of the $\mathrm{BGaN}$ sample compared to $\mathrm{GaN}$.

The evolution of the electrical current for the $\mathrm{BGaN} / \mathrm{GaN}$ SL sensors under intermittent flows of $450 \mathrm{ppm} \mathrm{NO}_{2}$ and pure $\mathrm{N}_{2}$ gas at $300^{\circ} \mathrm{C}$ and $5 \mathrm{~V}$ bias is exemplified in Fig. 3. The signal for the $\mathrm{BGaN} / \mathrm{GaN}$ SL device is shown to decrease to a steady-state value under $\mathrm{NO}_{2}$ proportional to the concentration, and to recover to the initial value under a flow of pure $\mathrm{N}_{2}$. The response time, $\tau_{r}$, was measured by allowing the signal to reach steady state under $\mathrm{NO}_{2}$ and calculating the time between $10 \%$ and $90 \%$ of the steady state value. At $300^{\circ} \mathrm{C}$, the response time was $5 \mathrm{~s}$ for the $\mathrm{BGaN} / \mathrm{GaN}$ SL device and was indeterminable for the GaN device due to the instability at this temperature. Measurements at $150^{\circ} \mathrm{C}$ showed response time for the $\mathrm{GaN}$ device on the order of a few minutes. The full recovery time, $\tau_{R}$, for the $\mathrm{BGaN} / \mathrm{GaN}$ SL device was measured to be $80 \mathrm{~s}$ at $300^{\circ} \mathrm{C}$.
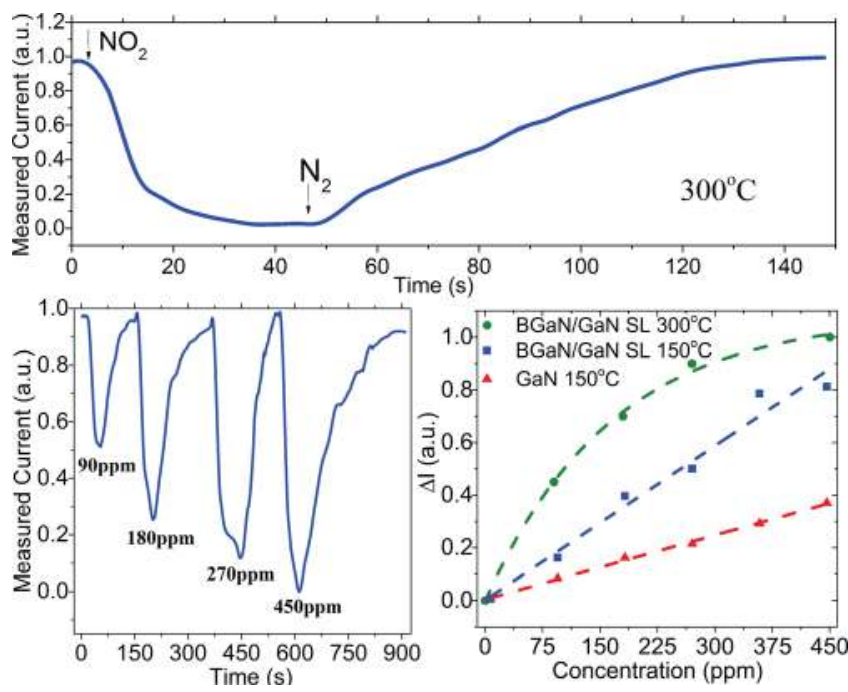

FIG. 3. Measured current (in arbitrary units) for the BGaN/GaN SL sensors under intermittent flows of $450 \mathrm{ppm} \mathrm{NO}_{2}$ and pure $\mathrm{N}_{2}$ gas at $300^{\circ} \mathrm{C}$ and $5 \mathrm{~V}$ bias (top), repeated between 90 and $450 \mathrm{ppm} \mathrm{NO}$ (bottom left), and $\Delta \mathrm{I}$ as a function of concentration for various temperatures, showing a linear response below $300^{\circ} \mathrm{C}$ (bottom right). 
The measurement was repeated with varying $\mathrm{NO}_{2}$ concentrations from 90 to $450 \mathrm{ppm}$ at $300^{\circ} \mathrm{C}$, showing that the $\Delta \mathrm{I}$ is a function of the concentration of gas (see bottom left of Fig. 3). We notice that at different concentrations, the recovery time is not always the same. This could be due to a difference in trap energies affecting the chemisorption of the gas. At this temperature, we begin to see saturation of the signal change leading to a nonlinear response for the $\mathrm{BGaN} /$ GaN SL as a function of concentration, whereas it remains linear at $150^{\circ} \mathrm{C}$ for both the BGaN/GaN SL and GaN monolayer devices (see bottom right of Fig. 3). This means that at higher temperatures and concentrations, it is possible to have a decrease in the responsivity of the device.

Finally, the BGaN/GaN SL device was tested in $15 \mathrm{ppm}$ of $\mathrm{NH}_{3}$, and showed no current change under the applied gas even at a temperature of $250{ }^{\circ} \mathrm{C}$. In contrast, we measured $0 \%-2 \%$ sensitivity to $0-15 \mathrm{ppm} \mathrm{NO}_{2}$ at the same temperature, indicating that the $\mathrm{BGaN} / \mathrm{GaN}$ SL device shows a very good selectivity between $\mathrm{NH}_{3}$ and $\mathrm{NO}_{2}$ at this concentration range. This has not yet been demonstrated by other SJ or MOSFET sensor devices. The GaN device was not responsive to $15 \mathrm{ppm}$ of either $\mathrm{NO}_{2}$ or $\mathrm{NH}_{3}$, most likely because this concentration of $\mathrm{NO}_{2}$ is below the detection limit of $\mathrm{GaN}$ sensor. We are currently investigating this phenomenon for other gases and concentration ranges as part of a separate study. The selectivity for the $\mathrm{BGaN} / \mathrm{GaN}$ SL device may be attributed to a different detection mechanism for $\mathrm{NH}_{3}$. One possible mechanism predicts that $\mathrm{NH}_{3}$ dissociation occurs most readily at triple points where the $\mathrm{Pt}$, semiconductor, and gas are all in contact simultaneously. ${ }^{9}$ Typically, these triple points require pores in the Pt layer; however, in the $\mathrm{BGaN} / \mathrm{GaN}$ SL device no pores can be observed due to the thick Pt contacts. Instead, we only see grain boundaries which allow $\mathrm{O}_{2}$ ion diffusion, but not $\mathrm{NH}_{3}$ dissociation/diffusion. Therefore, we may be able to alter the Pt thickness or morphology to obtain sensitivity to $\mathrm{NH}_{3}$ in addition to $\mathrm{NO}_{2}$, as well as further selectivity between different gases. This is currently being investigated.

In conclusion, we have shown that SJ gas sensors based on a BGaN/GaN SL structure exhibit high responsivity and a good balance between responsivity and sensitivity. At the same time, the sensitivity of the BGaN/GaN SL sensor is also significantly higher, making it the best choice for balancing the responsivity and sensitivity. This means that the BGaN/GaN SL sensor can be operated at a target detection limit while maintaining a higher signal-to-noise ratio (SNR) compared to the other sensors. Additionally, the BGaN/GaN SL sensor shows better thermal stability and a faster response time than the GaN-based sensor, and the ability to selectively detect between $\mathrm{NH}_{3}$ and $\mathrm{NO}_{2}$.

This work was supported by PSA Peugeot Citroën as part of the OpenLab of Metz, and by the Region of Lorraine. We would like to acknowledge Tarik Moudakir and Simon Gautier for their contribution to the materials growth, and Laurent Bouvot for device processing facilities.

${ }^{1}$ I. Lundstrom, M. S. Shivaraman, C. Svensson, and I. Lundkvist, Appl. Phys. Lett. 26, 55-57 (1975).

${ }^{2}$ I. Lundstrom, M. Armgarth, A. Spetz, and F. Winquist, Sens. Actuators 10, 399-421 (1986).

${ }^{3}$ J. Schalwig, G. Muller, M. Eickhoff, O. Ambacher, and M. Stutzmann, Mater. Sci. Eng., B 93, 207-214 (2002).

${ }^{4}$ M. Ali, V. Cimalla, V. Lebedev, H. Romanus, V. Tilak, D. Merfeld, P. Sandvik, and O. Ambacher, Sens. Actuators, B 113, 797-804 (2006).

${ }^{5}$ I. Lundstrom and C. Svensson, Solid State Chemical Sensors, edited by J. Janata and R. J. Huber (Academic, Orlando, 1985) p. 1-63.

${ }^{6}$ H. Hasegawa and M. Akazawa, Appl. Surf. Sci. 254, 3653-3666 (2008).

${ }^{7}$ S. A. Khan, E. A. de Vasconcelos, Y. Hasegawa, and T. Katsube, Braz. J. Phys. 34, 557-580 (2004).

${ }^{8}$ J. Schalwig, G. Muller, M. Eickhoff, O. Ambacher, and M. Stutzmann, Sens. Actuators, B 87, 425-430 (2002).

${ }^{9}$ I. Lundstrom, Sens. Actuators, A 56, 75-82 (1996).

${ }^{10}$ V. V. Quang, N. V. Dung, N. S. Trong, N. D. Hoa, N. V. Duy, and N. V. Hieu, Appl. Phys. Lett. 105, 013107 (2014).

${ }^{11}$ A. Spetz, M. Armgarth, and I. Lundstrom, J. Appl. Phys. 64, 1274-1283 (1988).

${ }^{12}$ T. Baghdadli, S. O. S. Hamady, S. Gautier, T. Moudakir, B. Benyoucef, and A. Ougazzaden, Phys. Status Solidi C 6, S1029-S1032 (2009).

${ }^{13}$ H. Srour, J. P. Salvestrini, A. Ahaitouf, S. Gautier, T. Moudakir, B. Assouar, M. Abarkan, S. Hamady, and A. Ougazzaden, Appl. Phys. Lett. 99, 221101 (2011).

${ }^{14}$ J. P. Salvestrini, A. Ahaitouf, H. Srour, S. Gautier, T. Moudakir, B. Assouar, and A. Ougazzaden, Proc. SPIE 8268, S1-S10 (2012).

${ }^{15}$ A. Ougazzaden, S. Gautier, C. Sartel, N. Maloufi, J. Martin, and F. Jomard, J. Cryst. Growth 298, 316-319 (2007).

${ }^{16}$ K. G. McKay, Phys. Rev. 94, 877-884 (1954). 